This item was submitted to Loughborough's Research Repository by the author.

Items in Figshare are protected by copyright, with all rights reserved, unless otherwise indicated.

\title{
Presence and quality of navigational landmarks: effect on driver performance and implications for design
}

PLEASE CITE THE PUBLISHED VERSION

PUBLISHER

(C) Human Factors and Ergonomics Society

LICENCE

CC BY-NC-ND 4.0

REPOSITORY RECORD

May, Andrew, and Tracy Ross. 2019. "Presence and Quality of Navigational Landmarks: Effect on Driver Performance and Implications for Design". figshare. https://hdl.handle.net/2134/2277. 


\section{Presence and Quality of Navigational Landmarks: Effect on Driver Performance and Implications for Design}

Andrew J. May, Tracy Ross

Ergonomics and Safety Research Institute, Loughborough University, Loughborough, United Kingdom

\section{Abstract:}

Current vehicle navigation systems still predominantly use distance-to-turn information to enable a driver to locate a forthcoming manoeuvre. It has been proposed that the design of driver navigation aids can be improved through the incorporation of landmarks as key navigation cues. However, little research has investigated how the quality of the landmark affects driver behaviour. An empirical field trial in a real traffic environment was undertaken with 48 participants (minimum age 21, mean 44; minimum driving experience three years; mean $\mathrm{km}$ driven in the last year 19,000) in order to assess the effect that the quality of a landmark had on driver behaviour when navigating an unfamiliar, complex, urban route. The use of good landmarks (as opposed to poor landmarks or distance information) as key verbal navigation cues resulted in significant improvements in navigation performance, driving performance, and driver confidence immediately preceding a turn. The use of distance information to locate a turn resulted in significantly more glances to the in-vehicle display. Actual or potential applications of this research include guiding the design of effective and safe future vehicle navigation systems.

\section{Contact address:}

Andrew May

Ergonomics and Safety Research Institute, Holywell Building, Holywell Way, Loughborough, Leicestershire, LE11 3UZ, UK

\section{Short Title:}

Driver Navigation using Landmarks

\section{Keywords:}

Vehicle Navigation, Landmarks, Driver Performance, Design 


\section{Presence and Quality of Navigational Landmarks: Effect on Driver Performance and Implications for Design}

\section{INTRODUCTION}

\section{Driver navigation}

One of the most demanding activities for drivers is navigating in an unfamiliar environment: studies have long identified the difficulties that drivers have in planning and following efficient routes (King, 1986; Streeter, 1986; Wierwille, Antin, Dingus, \& Hulse, 1989). If drivers are unable to navigate successfully, there is a range of individual and societal consequences including: driver frustration and anxiety (Barrow, 1991) and reduced mobility for those groups wary of travel in unfamiliar environments (Burns, 1997). In addition, there are potential increases in congestion and pollution: King (1986) found in an empirical study in the US that up to $20 \%$ of the miles driven could be considered 'navigation waste'. Jeffrey (1981) made a more conservative estimate that four percent of travel in the UK falls into this category. (Note: the term 'navigation' is used in this paper in preference to 'wayfinding', although 'wayfinding' more accurately describes the dynamic step by step decision making process (Passini, 1984) of a driver using a navigation system to reach a destination. )

Vehicle navigation systems (also termed satellite navigation or route guidance systems) offer a technological solution to aiding drivers navigation, and are increasingly a mainstream product in upper, mid-range, and commercial categories of vehicles (Rowell, 2001). Typical systems use a combination of satellite GPS and digital map-matching to calculate an optimum route to a specified destination. They then present a series of map overviews and turn-by-turn instructions to drivers, using a combination of auditory (verbal and non-verbal) and visual (text and graphics) information. A typical turn-by-turn instruction is an auditory 
'left turn in 300m', accompanied by a visual left turn arrow plus a distance-to-turn countdown bar that reduces to zero as a manoeuvre is approached.

Satellite navigation systems generally function extremely well (although of course they are wholly dependent on the completeness and accuracy of the underlying map database). However, from a human factors perspective, there are several potential limitations to their current design: their concept is based around that of procedural, paced information presentation to the driver; they generally use distance information to enable a driver to locate a turn; and some systems employ complex visual human-machine interfaces (as well as corresponding auditory information). The potential of visual displays to distract drivers has long been recognised (Lunenfield, 1989; Mollenhauer, Hulse, Dingus, Jahns, \& Carney, 1997; Wierwille, 1993); this is potentially exacerbated with navigation systems due to the dynamic presentation of detailed information and their possible use within complex driving environments.

\section{The role of landmarks in navigation}

It has been proposed that future navigation systems can be made more effective and safer by incorporating landmarks as key navigation cues (Burnett, 2000). Allen (1999) categorised human navigation into three basic forms: the commute, the explore and the quest (the latter defining navigation to an unfamiliar destination, as typically supported by a vehicle navigation system) and highlighted the importance of landmarks in a piloting strategy for a quest: 'Piloting involves landmark-based navigation .... A quest is often guided by route directions that consist of a listing of landmarks with actions designed to lead from one to another.'

As well as being important for piloting strategies, landmarks are also key components in cognitive maps (Hirtle \& Hudson, 1991; Hirtle \& Jonides, 1985), which is the other main strategy identified by Allen (1999) for navigation to an unfamiliar destination. Trowbridge 
(1913) is recognised as the first to describe the prevalence of what he termed 'imaginary maps' and described their role in the 'readiness of man to be confused with respect to a new environment' - underlining how these representations may be inaccurate representations of the real world. Tolman (1948) is considered the first to demonstrate empirically that animals (including humans) develop a spatial representation or 'cognitive map' of their environment, which is used within spatial problem solving activities such as navigation. Lynch (1960) also underlined the importance of landmarks in mental representations of a large scale environment. In a series of influential studies, he found that environments were categorised into five types of element: (1) Paths - defined as the channels along which people move; (2) Nodes - points where several paths meet, e.g. junctions; (3) Landmarks - external reference points which are easily observable from a distance; (4) Districts - the medium-to-large sections of an environment, which the observer mentally enters "inside of"; (5) Edges - linear elements that serve as boundaries between districts or other areas. Although more recent research has consistently demonstrated the importance of landmarks within cognitive maps, it has also shown how landmarks may also act as distorting elements within those maps (Holding, 1992; Sadalla, Burroughs, \& Staplin, 1980).

Landmarks therefore support the strategies used to navigate to unfamiliar destinations. By providing external reference points which are easily remembered and recognised, they can potentially reduce the need to refer to an information display in order to locate a navigation decision point.

\section{Definition of the landmark construct}

Landmarks have been defined from varying theoretical perspectives. As previously stated, Lynch (1960) described them as external reference points which are easily observable from a distance. Kaplan (1976) defined a landmark as "a known place for which the individual has a well formed representation", and outlined two theoretical factors that lead to a place or object 
acquiring landmark status: the frequency of contact with the object or place, and its distinctiveness. Three type of distinctiveness were hypothesised: visual distinctiveness (a predominantly objective quality relating to the physical attributes that discriminate it from the surrounding environment); inferred distinctiveness (knowledge concerning its structure or form that makes it stand out from what is usual); functional distinctiveness (the salience in terms of the goals or sub-goals of the individual). In addition to the visual characteristics of landmarks and their functional or social importance, the location of an object within the environment has also been shown to impact significantly on its effectiveness as a landmark (Allen, Siegel, \& Rosinski, 1978; Carr \& Schissler, 1969). Several studies have commented on the characteristics of landmarks that are useful for navigation purposes. Akamatsu, Yoshioka, Imacho, Daimon, \& Kawashima (1997) state that popular landmarks in their study were visible from a distance, unique in appearance, and close to or part of the road infrastructure. Green, Levison, Paelke, \& Serafin (1995) state that the best landmarks are those which can be seen from a distance, are close to the road, near junctions, and permanent. Burnett, Smith, \& May (2001) identified 5 attributes that were characteristic of 'good' landmarks for vehicular navigation: permanence, visibility, usefulness of location, uniqueness (incorporating distinctiveness), and ability to be described with brevity.

For the purposes of this study, landmarks were broadly defined as external reference points which were potentially useful to a driver as navigation cues. Four main constructs were assumed to be key determinants of the effectiveness of a landmark as a navigation cue: its visibility to an approaching driver, its familiarity to a typical driver, its uniqueness in terms of being dissimilar to other nearby objects, and the usefulness of its location when being integrated within other environmental information in order to support navigation at driver decision points. 


\section{The practical benefits of landmarks for driver navigation}

The importance of landmarks in driver navigation has also been shown by a number of studies. They have been shown empirically to be widely used within drivers' wayfinding strategies (Alm, 1990; May, Ross, \& Bayer, 2003), and valued by drivers as information cues (Burns, 1997; Streeter, 1986; Wochinger \& Boehm-Davis, 1997).

The potential benefits of landmarks are relatively well established. A range of studies has empirically demonstrated how landmarks have the potential to enhance driver navigation systems in terms of: (1) effective navigation decisions (Tom \& Denis, 2003; Jackson, 1998; Bengler, Haller, \& Zimmer, 1994); (2) reduced cognitive effort and distraction (Burnett, 1998), and (3) increased confidence and satisfaction (Alm, Nilsson, Jarmark, Savelid, \& Hennings, 1992; Green, Hoekstra, Williams, Wen, \& George, 1993). However, little, if any, research has been published that assesses the extent to which driver performance, within a real navigation context, is affected by the quality of the landmark, i.e. the extent to which it is a 'good' or 'poor' navigational cue based on key physical and contextual factors.

\section{Research questions}

The primary aim of this study was to investigate, within a real driving environment, the impact on driving and navigating performance of providing landmark information of varying quality within drivers' navigation instructions. In particular, the study assessed: (1) the potential benefits and dis-benefits of using landmarks (as opposed to distance information) as the key auditory navigation information used to locate a forthcoming manoeuvre in an unfamiliar area; and (2) the impact of the 'quality' of a landmark when navigating and driving a complex, unfamiliar route. It was anticipated that providing good landmarks in verbal turn instructions would result in safer driving and better navigation performance than either poor landmarks or distance to turn information. However, it was not evident the extent to which performance would be degraded with the use of relatively poor landmarks. This 
study therefore provided empirical evidence which can be used to make informed decisions about the information to be included as navigation cues in future vehicle navigation aids.

\section{METHOD}

\section{Overview}

This study comprised a road-based trial to assess driver navigation and driving performance with a modified vehicle navigation system that included landmarks within its instructions. Three different groups of participants used the navigation system to navigate around a complex urban route using navigation instructions which included either (1) 'good' landmarks, (2) 'poor' landmarks or (3) distance information within the auditory information presented to a driver. A range of driver behaviour measures were collected, including visual glance data, driving errors, driver workload, navigation errors, navigation confidence, and pre and post-trial driver attitudinal responses.

\section{Apparatus}

A Land Rover Freelander ${ }^{\mathrm{TM}}$ was used which was fitted with a state of the art, DVD-based satellite navigation system that provided visual and verbal turn instructions, and map overview information, to enable a driver to navigate to one or more specified destinations. On approach to each of the manoeuvres en-route, the satellite navigation system displayed a direction arrow integrated into a simplified junction overview and also incorporated a distance countdown bar that showed the distance to the turn (starting at 500 metres and counting down to zero in $50 \mathrm{~m}$ increments), the name of the current road and the name of the road being turned into (Figure 1). In between manoeuvres, the visual display presented a map overview to the driver.

$<$ INSERT FIGURE 1 ABOUT HERE $>$ 
In order to incorporate landmark information within the voice instructions, three sets of auditory prompts were recorded that either included 'good' landmarks, 'poor' landmarks or distance to turn information. The selection of 'good' and 'poor' landmarks was based on the assessment of potentially available landmarks against the main attributes discussed above as those which determine their suitability (quality in use) for navigation purposes: visibility, familiarity, uniqueness and location.

With respect to the latter three attributes, landmarks were selected which were all: familiar and relatively permanent features of the built environment, unique such that they would not be confused with other instances of the same object, or other similar objects, and located at or within $20 \mathrm{~m}$ of the relevant junction. In addition, they were all common, easily recognisable objects such as petrol stations, as opposed to being unique objects such as individual restaurants, to prevent the need for memorisation of new information cues. The differentiation between 'good' and 'poor' landmarks was based on the distance at which they became visible and recognisable to an approaching driver on a clear day. This visible distance assessment was undertaken for each landmark independently by three raters with normal or corrected to normal eyesight, whilst driving the route in fine weather, and the median rating from these assessments used. The 'good' landmarks at the eight target manoeuvres were visible at a mean distance of $212(\mathrm{SD}=83) \mathrm{m}$; the 'poor' landmarks at those same target manoeuvres were visible at a mean distance of $103(\mathrm{SD}=46) \mathrm{m}$. Typical 'good' landmarks were traffic lights, pedestrian lights and petrol stations. Typical 'poor' landmarks were bus stops, post boxes and phone boxes. These are listed in Table 1.

These messages were triggered and played to the driver in lieu of the auditory output generated automatically by the navigation system, to enable participants to navigate the trial route. The messages consisted of up to three verbal prompts as follows: a Preview 1 message given at the earlier of $500 \mathrm{~m}$ or the completion of a prior manoeuvre (this was omitted if 
subsequent manoeuvres were closer than $300 \mathrm{~m}$ ); a Preview 2 message given at the earlier of $200 \mathrm{~m}$ or the completion of a prior manoeuvre; a Final auditory tone (beep) given at $50 \mathrm{~m}$ to the manoeuvre. This presentation strategy is typical of that employed by current vehicle navigation systems incorporating distance information. A typical auditory message that included a landmark was 'turn right after the Texaco ${ }^{\mathrm{TM}}$ petrol station', i.e. it included no distance-to-turn information.

To preserve face validity, where landmarks were present at incidental manoeuvres, they were presented to the driver at these locations; however these landmarks were not defined as 'good' or 'poor' and this data was not analysed. Where landmarks were not present at incidental manoeuvres, verbal distance to turn information was given for all participants. Visual distance to turn information was given for all participants at all manoeuvres, as shown in Figure 1.

\section{Participants}

Forty eight participants were recruited from the general public via web notice boards, local newspaper advertisements and posters. They were all over 21 with self-reported normal or corrected-to normal vision, held a clean driving licence, had driven regularly for at least three years, not previously used a navigation system, and did not know the area where the study took place. A pre-screening exercise enabled potential participants to be balanced for factors shown to potentially influence navigation performance, driving behaviour and/or information preferences: age (Burns, 1998; Walker, Alicandri, Sedney, \& Roberts, 1991); gender (Burns, 1998; Ward, 1986), and self-reported navigation ability (Allerton, 2000; Streeter, 1986). In addition, participants were also matched on self-reported distance judgment ability, since this skill was fundamental in interpreting the distance countdown bar on the display, has been shown to vary considerably within the population (Fine \& Kobrick, 1983), and be negatively impacted by concurrent task demands (Boeoek \& Gaerling, 1978). Participants were then 
randomly allocated to one of the three between subjects experimental conditions. They were paid $£ 20$ for their participation.

\section{Experimental route}

A experimental route was chosen based around the south of Leicester, a city in the UK with approximately 320,000 inhabitants. It was explicitly designed to be navigationally challenging, having 37 driver decision points within its $17.5 \mathrm{~km}$ length. A driver decision point was defined as a location where a driver had more than one navigation option and was not following a single major traffic flow, or had to potentially stop or give way to other traffic. In practice, these were geographical locations where a lack of navigation information could result in a navigation error, or navigation uncertainty. The route was an urban/suburban route comprising 10\% dual carriageway and $90 \%$ single carriageway. Approximately $75 \%$ was residential housing, $25 \%$ being urban (but not city centre) retail/commercial. The route took approximately 40 minutes to drive, the speed limit on the majority of the route being $50 \mathrm{kph}$. The route was chosen on the basis of eight target manoeuvres that met the following criteria: a left or right turn off the main route; other potential turns nearby (i.e. a requirement for information to precisely locate the manoeuvre); a good and a poor landmark that could be used to identify the turn; preferably at least a $500 \mathrm{~m}$ approach to allow for the presentation of three auditory messages. The target manoeuvres, plus accompanying good and poor landmarks are summarised in Table 1.

\section{$<$ INSERT TABLE 1 ABOUT HERE $>$}

There were an additional 25 manoeuvres en-route; these were incidental and merely served to link the target manoeuvres into a continuous circuit. Participants were unaware that there were target and non-target manoeuvres. 


\section{Experimental Design}

The experimental design was a 3(Information) x 8(Manoeuvre) mixed design. Information was a between subjects factor representing the nature of the verbal information provided to a participant, i.e. whether the auditory component of the navigation instructions incorporated: (a) distance-to-turn information (as per current navigation systems), (b) good landmarks, or (c) poor landmarks (instead of distance information) to locate a turn. Manoeuvre was a within subjects factor representing the eight target manoeuvres en-route, thereby enabling investigation of behavioural changes due to the variability of the characteristics of individual manoeuvres. Due to the constraints of driving an actual route with a real navigation system, it was not possible to randomise or balance the within-subjects factor, i.e. all participants completed the target manoeuvres in a set order. All trials took place mid morning or mid afternoon (i.e. off-peak traffic conditions).

\section{Dependent variables}

The data captured in the study measured driver safety, navigation performance, workload, driver confidence and driver attitudes. Visual glance behaviour was measured via video capture in order to determine the number and duration of glances to the in-vehicle visual display during the $500 \mathrm{~m}$ approach to each manoeuvre. The time that each participant spent moving and spent stationary (e.g. whilst queuing in traffic) was determined for each participant from the video analysis. The stationary glances (comprising less than $10 \%$ of the total) were not included in subsequent analysis as their mean duration was $65 \%$ higher than the moving glances, and some very long stationary glances were made (maximum $4.2 \mathrm{~s}$ ). The percentage moving time metric was used to account for the speed variations in the approach to particular manoeuvres: the total moving time, upon which this metric was based, was measured separately for each participant at each manoeuvre. Correspondingly, the percentage 
moving time metric was calculated as the total duration of the glances to the display whilst moving, divided by the total time spent moving during the approach to each manoeuvre.

Driving errors during the approach to each manoeuvre were assessed by a UK Driving Standards Agency Approved Driving Instructor who accompanied each participant during the trial (and was unaware of the exact nature of the independent variable manipulation). Errors were recorded as minor, serious or dangerous using a checklist developed in conjunction with the driving instructor. This employed six error categories as used in the UK Driving Examination: (1) use of mirrors and rear observation when signalling, changing direction and speed; (2) appropriate use of signals (indicators); (3) response to signs and signals including traffic signs, road markings, traffic lights, traffic controllers and other road users; (4) junctions, including speed of approach, observation, turning left or right and cutting corners; (5) positioning in normal driving and lane discipline; (6) awareness and planning. Driving errors that participants committed were therefore recorded as minor, serious or dangerous within the six error categories above. A minor error was one that was not in itself potentially dangerous unless it was habitual. A serious driving error was one where potential danger had occurred. A dangerous error was one involving actual danger to the driver/passenger or other road users. These are exemplified in relation to a UK driver (driving on the left) turning right into a more minor road. If the driver turned early, cutting the corner, without full observation of the road being turned into and there were no parked vehicles or obstructions near to the junction it would be considered a minor driving fault. However if the driver continued to turn right in this manor it would be considered habitual and therefore categorised as a serious driving fault. If there were parked cars close to the junction such that the driver had to brake and/or steer suddenly to avoid them, this would be considered serious in its own right. If the driver cut the corner and there was a moving car approaching the junction such that either one 
or both of the cars had to brake or steer suddenly to avoid a collision, this would be classified as a dangerous error.

All actual and near navigation errors were recorded. 'Near' navigation errors were those where a participant showed clear intention (e.g. a lane change or onset of indicators) to take an incorrect turn, even though they may have subsequently corrected this and completed the manoeuvre correctly.

Driver workload was assessed on completion of the experimental route using a slightly adapted version of the NASA RTLX (Hart \& Staveland, 1988) subjective workload assessment tool. This included a scale to measure perceived distraction (Fairclough, 1991).

Driver confidence (after receiving each verbal instruction) was measured at approximately 450, 150 and $30 \mathrm{~m}$ from each target and non-target manoeuvre by application of a simple verbal subjective rating procedure which determined the driver's assessment of their confidence in relation to the extent they 'know where to turn and will be able to complete that manoeuvre successfully'. After completing each manoeuvre, participants gave an additional confidence rating to indicate their confidence that they had taken a correct turn.

Drivers' beliefs and evaluative attitudes, and their temporal changes, were assessed using a three part questionnaire based largely on five point agree-disagree Likert Scale responses. This was administered pre-trial, part-way through, and post-trial. Since the focus of this paper is on driver performance, rather than attitude formation, these results are not reported.

\section{Procedure}

On arrival, participants were introduced to the study, signed consent forms and completed part one of the questionnaire. After familiarising themselves with the vehicle controls, the participants completed a mixed-road familiarisation drive lasting approximately 25 minutes. They then drove for about 10 minutes using the vehicle navigation system, receiving approximately eight navigation instructions during this period, and then undertook a practice 
session lasting a further 10 minutes where they drove using the navigation system and gave confidence ratings at five manoeuvres. All participants were able to complete this familiarisation process successfully and without requesting additional practice time, which was offered in all cases.

After familiarisation and training (lasting approximately 45 minutes), the participants drove the trial route using the navigation system with simulated auditory output, giving the three pre- and one post-manoeuvre confidence ratings; they were occasionally prompted if necessary. During the approach to each manoeuvre, the nature and severity of any driving errors were recorded by the driving instructor, and navigation errors were recorded. Part two of the questionnaire was completed after 5 minutes of the test route. The participant then navigated the rest of the test route and the modified NASA RTLX and part three of the questionnaire were completed before the participant was debriefed and paid.

\section{ANALYSIS AND RESULTS}

\section{Visual behaviour}

Visual glance analysis was undertaken for the eight target manoeuvres of interest. Figures $2 a \& 2 b$ show the mean number of glances to the navigation display whilst the driver was moving, and the percentage moving time metric (total time spent glancing to the display while moving, as a percentage of the time spent moving) during the $500 \mathrm{~m}$ approach to a manoeuvre, according to whether participants used auditory navigation instructions employing good landmarks, poor landmarks or distance information to locate a turn.

\section{$<$ INSERT FIGURE 2 ABOUT HERE $>$}

Each of the above variables comprised a within subjects component that represented the eight target manoeuvres. The data for the within subjects factor of Manoeuvre showed nonsphericity, therefore a MANOVA was used, analysing all of the target manoeuvres 
simultaneously (results are reported based on Wilks' Lambda). (Similar results were obtained using a univariate repeated measures analysis with results adjusted for lack of sphericity by using the Huynh-Feldt Epsilon correction).

The information used to locate a manoeuvre (i.e. whether the auditory navigation instructions contained good landmarks, poor landmarks or distance information) affected the mean number of glances made to the display during the approach to the manoeuvre, $F(4.135,74)=4.135, p<.001$, and the percentage of time that participants spent looking at the display during the approach to a manoeuvre, $F(16,74)=4.393, p<.001$, but had no impact on mean glance duration. Analysis of the eight individual target manoeuvres indicated significant effects (at $p<.05$ ) of information category on: the number of glances made to the display and the percentage moving time spent looking at the display for all eight target manoeuvres bar the first one.

Tukey HSD post hoc tests $(\alpha=.05)$ showed that using distance information to locate a turn resulted in a significantly greater number of glances being made to the display for seven out of the eight target manoeuvres (and a marginal effect for the $8^{\text {th }}$ ) when compared to poor landmarks, and for five out of the eight target manoeuvres when compared to good landmarks. There was one manoeuvre where using good landmarks resulted in a greater number of glances than using poor landmarks, and another where there was a similar marginal effect. At all other manoeuvres, there were no differences between good and poor landmarks. Similar post hoc test results were achieved for the percentage moving time measure.

\section{Driver confidence}

The empirical data consisted of four confidence ratings of low, medium or high (coded as 1, 2, 3 respectively) derived from three distinct points during the approach to, and one immediately after, each of the 33 manoeuvres on route. Figure 3 shows the change in mean 
subjective confidence level across all eight target manoeuvres, at each of the four confidence points, according to whether participants used good landmarks, poor landmarks or distance information to locate the turn.

\section{$<$ INSERT FIGURE 3 ABOUT HERE $>$}

A Kruskal-Wallis test for 3 independent samples showed that the information used to locate a turn had a significant impact on the confidence of the driver at the Preview 1 point, $\chi^{2}(2)=8.484, p=.014$, the Preview 2 point, $\chi^{2}(2)=8.049, p=.018$, and a marginal impact at the Final point $\left(\chi^{2}(2)=5.856, p=.053\right.$, but no impact on driver confidence post-manoeuvre. Multiple independent sample paired comparisons (Siegel \& Castellan, 1988, p. 213), ( $\alpha$ $=.05$ ) were undertaken to compare driver confidence at each of the confidence rating points, dependent on whether drivers used good landmarks, poor landmarks or distance to locate a turn. At the Preview 1 and Preview 2 point, participants using distance were more confident than those using poor landmarks to locate a turn. At the Final preview point, the good landmark group were marginally more confident than the poor landmark group. There were no other statistically significant differences, although Figure 3 indicates some potential trends in the data (note this figure shows mean confidence ratings, not mean ranking data).

Based on a Friedman test for 3-related samples, driver confidence increased during the approach to a manoeuvre for the participants using good landmarks $\left(\mathrm{N}=16, \chi^{2}(2)=19.6, p<\right.$ $.001)$ and poor landmarks $\left(\mathrm{N}=16, \chi^{2}(2)=19.966, p<.001\right)$ to locate a turn. There was no significant increase in confidence when using distance information to locate a turn.

\section{Driving errors}

In conjunction with the driving instructor, a coding scheme was devised whereby a score of one was assigned to each minor error a driver committed, a five to a serious error, and a 10 
to a dangerous error. This was based on the pass/fail criteria for the UK driving test, plus the driver instructor assessment of habitual driving errors representing dangerous driving.

Driving errors were aggregated for each participant over all eight target manoeuvres. Figure 4 shows, for each participant group, the contribution of each level of error to the total score, aggregated across target manoeuvres, according to whether participants were using good landmarks, poor landmarks or distance information to locate a turn.

\section{$<$ INSERT FIGURE 4 ABOUT HERE $>$}

A Kruskal-Wallis test for 3 independent samples showed that the information used to locate a turn had a significant impact on the total driving error scores $\left(\chi^{2}=7.337, \mathrm{df}=2, p=\right.$ .026). Multiple independent sample paired comparisons (Siegel \& Castellan, 1988, p. 213), ( $\alpha$ $=.05$ ) indicated that participants using good landmarks produced a lower total driving error score than those who used poor landmarks. An analysis of the minor, serious and dangerous error scores showed that the information used to locate a turn had a significant impact on the serious error scores $\left(\chi^{2}=10.173, \mathrm{df}=2, p=.006\right)$, with no statistically significant differences for the minor or dangerous error categories.

An analysis was undertaken on each of the six individual driving error categories: observation; use of indicators; response to signs and signals; performance at junctions; vehicle positioning; awareness and planning (described more fully in the Methods section in this article). A significant effect was found for Indicator error score, $\chi^{2}(2)=13.309, p=.001$; the above multiple comparison technique indicated that participants using good landmarks achieved a significantly lower indicator error score than those using poor landmarks and those using distance to locate a turn. No statistically significant differences were found for other driving error categories. 


\section{Driver workload}

The data from the the NASA-RTLX constructs were combined with an equal weighting as per Nygren (1991). The information used to locate a turn made no difference to the perceived total driver workload.

\section{Navigation performance}

Actual or near navigation errors were aggregated for each participant over all eight target manoeuvres. Figure 5 shows these results, according to whether participants were using good landmarks, poor landmarks or distance information to locate a turn.

\section{$<$ INSERT FIGURE 5 ABOUT HERE $>$}

A Kruskal-Wallis test for three independent samples showed that the information used to locate a turn had a significant impact on the number of navigation errors made $\left(\chi^{2}(2)=\right.$ 18.749, $p<.001)$. The multiple paired comparison technique described by Siegel \& Castellan (1988, p. 213), $(\alpha=.05)$ indicated that participants using good landmarks committed fewer [actual or near] navigation errors than those using poor landmarks or distance information to locate a turn.

\section{DISCUSSION}

\section{Visual glance behaviour}

Incorporating landmarks within the verbal navigation instructions resulted in a $40 \%$ decrease in the number of glances made to the display during the approach to the target manoeuvres. This reduction in the number of glances whilst using landmarks was consistent with the results of Burnett (1998) who found that emphasising landmarks (as opposed to distance) within a vehicle navigation system resulted in a reduction of glances during the approach to a manoeuvre from a mean of 5.0 to 1.6. A greater effect probably arose during 
the study by Burnett (1998) due to landmarks in that study also being represented on the visual display, as well as being contained within the verbal instructions.

Within the present study, when landmark information was not available to the driver, frequent glances were made to the distance countdown bar in order to locate a turn. Where landmark information was provided within turn-by-turn instructions, it was apparent that participants used a range of strategies to locate a turn. Most participants made initial glances to the display when they received the first verbal instruction at about $500 \mathrm{~m}$ from the manoeuvre, and then looked again at the display during the final approach to a manoeuvre. However, it was interesting that some participants made no glances to the display for particular manoeuvres when using landmarks (compared to a minimum glance frequency of four when using distance), underlining the potential for navigation systems that place minimal reliance on provision of information via a visual display.

One of the most obvious indicators of the safety implications of an in-vehicle display is the total amount of time spent looking at that display. Figure $2 \mathrm{~b}$ shows that using landmarks (good and poor aggregated, and compared to distance) to locate a turn reduced the percentage of time spent looking at the in-vehicle display by approximately $40 \%$, due to the reduction in the number of glances made to the display.

An interesting finding was that a larger number of glances were made to the display when using good landmarks as opposed to poor landmarks to locate a turn. This could potentially question the definition of landmarks as 'good' or 'poor' since it indicates less eyes-on-road time for good external information cues as opposed to poor ones. However since there was no visual representation of the landmarks on the visual display, a likely explanation for this unexpected result is that demand-driven (but resource-limited) visual search behaviour resulted in participants directing greater visual attention to the roadside when searching for poor landmarks (good landmarks were easier to see), with subsequent reduction in attention 
to the visual display. In effect, since the display was not needed for those drivers using landmarks, participants searching for poor landmarks were too visually engaged with the external road scene to look at the visual display.

Visual glance behaviour was differentially impacted at the target manoeuvres according to the type of information presented to the driver. At five manoeuvres there was an increase in the number of glances when using distance to locate the turn (compared with good and poor landmarks); at three manoeuvres there was a reduction in the number of glances when using poor landmarks to locate the turn (compared with good landmarks or distance information). Although difficult to interpret with certainty, the relative increase in visual glances when using distance information occurred at those turns which were partially obscured, and hence difficult to locate via visual search without reference to a landmark. In contrast, the reduction in glances with poor landmarks occurred at turns where the turn itself was relatively visible, but the poor landmark was particularly difficult to locate, with greater exterior visual search being required (and hence a compensatory reduction in glances to the display). In practice the visual glance behaviour, and differential impact of information provision to the driver will be contextually dependent on a range of factors such as the visibility of the manoeuvre, speed of traffic, drivers expectations (of where the next manoeuvre is likely to be) and the nature and location of the landmark.

In this study, the visual component of the information provision was kept constant throughout the study in order to prevent a confounding of the display-induced visual demand on the driver. However this then resulted in an inconsistency of information display to the driver when using landmarks (visual distance and verbal landmarks). This is likely to have reduced the differential effect of the independent variable: a graphical representation of landmarks would have increased the ease of visually identifying the landmark, and further reduced the need to refer to distance on the visual display. In reality, the visual complexity of 
a landmark-featured navigation system could be reduced, with a concomitant decrease in the visual demand induced by such a system.

\section{Driver confidence}

Driver confidence during the initial stages (at approximately $450 \mathrm{~m}$ ) of an approach to a manoeuvre was higher when good as opposed to poor landmarks were used to locate the turn, but in general, lower than when distance information was used instead. This is shown in Figure 3, which also clearly shows the increase in confidence over the approach to a manoeuvre for good and poor landmarks, and the comparison with the relatively stable confidence levels when using distance information.

Alm et al. (1992) have found landmarks to improve driver confidence regarding where to turn. However the present study additionally investigated changes in confidence over the approach to a manoeuvre. Due to the urban driving environment (with complex road geometries, roadside furniture, parked cars etc), in most cases the landmark being used to locate a turn was not visible at the Preview 1 message point which was typically given at 450-500 $\mathrm{m}$ from the manoeuvre (the average distance from the turn at which the good landmarks were visible was $212 \mathrm{~m}$; for the poor landmarks, this was only $103 \mathrm{~m}$ ). The type of information, and the quality of any landmark used (as operationalised within this study), therefore appear to have a direct impact on a driver's confidence on approaching a manoeuvre. There was no differential impact post-manoeuvre: as long as the street name was present and visible, participants were able to use the visual display to confirm that they had taken the correct turn.

\section{Driving errors}

The aggregated driving error scores showed that auditory instructions employing good landmarks resulted in a significantly lower total error score than using either poor landmarks 
or distance to locate a turn (Figure 4). Results regarding the inappropriate use of signals (i.e. turn indicators), are consistent with other studies that have looked at the effect on driving errors of including landmarks in navigation instructions (Bengler et al., 1994; Philips, 1999). No statistically significant differences were found for other driving error categories; however the results suggest the potential safety benefits of using good landmarks to locate turns, since the highest score in each of the error categories always arose as a result of using either poor landmarks or distance to locate a turn. Analysis of the differences in the error severity (i.e. minor, serious or dangerous) contributing to the overall error score indicated that it was the error score arising from 'serious' errors which differed according to the information presented to the driver. This suggests that differences in the total error score were not merely due to differing driving styles (e.g. braking late for manoeuvres or rarely using turn indicators), as this would have resulted in disproportionate 'errors' within the minor error category.

\section{Driver workload}

The results for perceived driver workload failed to detect any differences according to whether drivers were using good landmarks, poor landmarks or distance information to locate a turn. The NASA-RTLX has been successfully employed within driving research to demonstrate effects due to a range of independent variables such as form or modality of information presentation (Lee, Caven, Haake, \& Brown, 2001), and early navigation studies (e.g. Alm et al., 1992) have shown that drivers' mental workload was lower when including landmarks in navigation instructions. There are several potential explanations as to why no differences in driver workload were detected in this study: (1) to ensure face validity, a manipulation of the independent variable (and therefore expected differences in workload) only occurred at those manoeuvres where landmarks were present, whereas the NASA-RTLX was completed at the end of the route taking into account all manoeuvres; (2) unlike previous 
studies, the visual information was held constant across the independent variable manipulation, therefore the variation in cognitive demand arising from the independent variable was likely to be less; (3) any minor effects on workload were likely to be masked by isolated traffic incidents due to the situated context of the study. It was likely that the verbal confidence rating process that the drivers undertook at each manoeuvre increased their mental workload, in addition to the navigation task they were undertaking. Although this was a potential confounding factor, there was no reason why this should have differentially impacted on any one of the participant groups.

\section{Navigation errors}

Participants using good landmarks made far fewer (actual or near) navigation errors than those using either poor landmarks or distance information to locate a manoeuvre, as can be seen in Figure 5. Taking into account the total number of target manoeuvres undertaken (i.e. those manoeuvres where a distinction was made between landmarks and distance information), the percentages of navigational errors made were: good landmarks ( $2 \%)$, poor landmarks (11\%) and distance information (13\%). The potential navigation benefit of good landmarks mirrors the results of other studies including Alm et al. (1992) and Bengler et al. (1994) although these studies did not explicitly differentiate between good and poor landmarks. In practice, the absolute error rates reported in this study are unlikely to be as high within a real-use context, since the experimental route employed was deliberately chosen to be challenging, and participants were chosen who had no prior experience of using navigation systems (they were therefore more representative of first-time rather than experienced navigation system users). 


\section{Limitations to the study}

There were several potential limitations to the study. This road study suffered from the typical lack of control over potentially confounding factors, and the usual limitations of a cross-sectional, rather than longitudinal, design. However the mixed design enabled temporal changes in the dependent variables to be identified, and these are reported where appropriate. The main threats to reliability and validity arise from the multipliers used within the driving error score assessments, and the individual interpretation of the driver confidence construct (it could be argued that this actually represented an overall 'wellbeing' rating). However, the driver error results are consistent with previous research discussed above. In addition, the impact of Information category on driver confidence has intra-study consistency with the landmark visibility and participant attitudinal data (not reported since the focus of this paper was the behavioural impact of including landmarks within navigation instructions).

The study incorporated several key balancing variables in order to match participants across the main between subjects factor (whether they received good landmarks, poor landmarks or distance information in the verbal instructions). This increased the confidence in the analysis of the impact of the main independent variable. However, since the balancing variables of navigation ability and distance judgement were only self-reported, they were not analysed as independent variables in their own right. It is recommended that future studies of this nature might objectively quantify these variables in order to assess their impact on driving and navigational performance.

\section{SUMMARY AND CONCLUSIONS}

The main findings arising from this road study were that when good landmarks (as opposed to poor landmarks or distance information) were used to locate forthcoming manoeuvres, navigation performance, driving performance, and driver confidence immediately preceding (e.g. at $30 \mathrm{~m}$ from) a turn, were all increased. The use of distance 
information (as compared to landmarks in general) resulted in greatest reliance on an invehicle display, but the highest driver confidence during the early stages of an approach (e.g. from $450 \mathrm{~m}$ to $200 \mathrm{~m}$ ) to a manoeuvre. The use of poor landmarks resulted in lowest driver confidence at this point. The information used to locate a manoeuvre had no impact on subjective driver workload or post-manoeuvre confidence.

The chief design recommendation that arises from this study is that navigation systems are developed that do not require that a driver uses distance-to-turn information to locate a forthcoming manoeuvre. A hybrid approach may be most beneficial, where distance to turn information is used to create initial driver confidence, and good landmarks used when they become clearly visible. Although landmarks are a natural component within human navigation strategies, they will only be beneficial if they are good landmarks, taking into account their visual characteristics, the perception of them by potential users, their location in relation to the road network and the physical properties of the built and traffic environment, such that drivers can see, recognise and use them as navigation cues.

Although the potential benefits of landmarks have been demonstrated, there are several fundamental issues that must be addressed before they can be successfully incorporated within next generation navigation systems: (1) The concepts that future navigation systems should employ, e.g. whether future navigation systems are based on proceduralised turn-byturn instructions, or a dynamic, resource managing 'travel assistant' that increases the context-dependent relevance (and hence added value) of information. Future systems could adapt to the availability of particular navigation cues such as landmarks and direction signs, and tailor the delivery of navigation instructions based on the need for explicit new instructions at driver decision points. A future navigation system could therefore use a combination of turn-by-turn instructions which may include landmarks as key locators, as well as using a less paced delivery of navigation instructions based on following road signs, 
where routes or sections of routes are clearly signposted. In this latter case, landmarks may be relatively superfluous. (2) The implementation of such context-dependent systems, e.g. how the factors relating to context of use and information quality are measured or predicted, and how these are incorporated into system algorithms. (3) The content, depth and accuracy of information that is needed in navigable map databases in order to present landmarks to drivers, and the implications for collating, maintaining and enhancing this data.

This study has shown that although incorporating landmarks within navigation systems can enhance a driver's safety and navigation performance, a key prerequisite is to distinguish between good and poor landmarks. The incorporation of poor landmarks within navigation systems is likely to be worse than not using them at all.

\section{ACKNOWLEDGMENTS}

Support for this study was provided by an EPSRC research grant from the UK Government. The authors also wish to acknowledge the valuable assistance of Derek Brutnell, Nick Smith, Jason Duffield, and Sebastian Paszkowicz. 


\section{REFERENCES}

Akamatsu, M., Yoshioka, M., Imacho, N., Daimon, T., \& Kawashima, H. (1997). Analysis of driving a car with a navigation system in an urban area. In Y. I. Noy (Ed.), Ergonomics and safety of intelligent driver interfaces (pp. 85-96). Mahwah, NJ: Lawrence Erlbaum Associates.

Allen, G. L. (1999). Cognitive Abilities in the Service of Wayfinding: A Functional Approach. Professional Geographer, 51(4), 554-561.

Allen, G. L., Siegel, A. W., \& Rosinski, R. R. (1978). The role of perceptual context in structuring spatial knowledge. Journal of Experimental Psychology, 4(6), 617-630.

Allerton, J. E. (2000). Tailoring Vehicle Navigation Systems to Individual and Environmental Factors - a A Road Based Study. Unpublished MSc thesis, Loughborough University, Loughborough.

Alm, H. (1990). Drivers' cognitive models of routes. In J. A. Rothengatter (Ed.), Laboratory and field studies on route representation and drivers' cognitive models of routes (DRIVE II V1041 GIDS, Deliverable GIDS/NAV2) (pp. 35-48). Groningen, The Netherlands: University of Groningen, Traffic Research Centre.

Alm, H., Nilsson, L., Jarmark, S., Savelid, J., \& Hennings, U. (1992). The effects of landmark presentation on driver performance and uncertainty in a navigation task - a field study (No. S/IT-4): (Swedish Prometheus, Tech. Rep. No. S/IT-4). Linköping, Sweden: VTI.

Barrow, K. (1991). Human factors issues surrounding the implementation of in-vehicle navigation and information systems (SAE Tech. Paper Series No. 910870). Warrendale, PA: Society of Automobile Engineers. 
Bengler, K., Haller, R., \& Zimmer, A. (1994). Experimental optimisation of route guidance information using context information. Paper presented at the First World Congress on Applications of Transport and Intelligent Vehicle Highway Systems, Paris, France.

Boeoek, A., \& Gaerling, T. (1978). Processing of information about location during locomotion: Effects of a concurrent task and locomotion patterns.

Burnett, G. E. (1998). "Turn right at the King's Head": Drivers' requirements for route guidance information. Unpublished $\mathrm{PhD}$ thesis, Loughborough University, UK.

Burnett, G. E. (2000). 'Turn right at the traffic lights': The requirement for landmarks in vehicle navigation systems. Journal of Navigation, 53(3), 499-510.

Burnett, G. E., Smith, D., \& May, A. J. (2001). Supporting the navigation task: characteristics of 'good' landmarks. Paper presented at the Contemporary Ergonomics 2001: Proceedings of the Annual Conference of the Ergonomics Society. London: Taylor and Francis.

Burns, P. C. (1997). Navigation and the older driver. Unpublished PhD thesis, Loughborough University, Loughborough, UK.

Burns, P. C. (1998). Wayfinding errors while driving. Journal of Environmental Psychology, 18, 209-217.

Carr, S., \& Schissler, D. (1969). Perceptual selection and memory in the view from the road. Environment and behaviour, 1(1), 7-35.

Fairclough, S. H. (1991). Adapting the TLX to Measure Driver Mental Workload (DRIVE Project V1017 (BERTIE) No. Report no. 71). Loughborough, UK: HUSAT Research Institute.

Fine, B. J., \& Kobrick, J. L. (1983). Individual differences in distance estimation: Comparison of judgments in the field with those from projected slides of the same scenes. Perceptual-and-Motor-Skills, 57(1), 3-14. 
Green, P., Hoekstra, E., Williams, M., Wen, C., \& George, K. (1993). Examination of a videotape-based method to evaluate the usability of route guidance and traffic information systems (Final No. UMTRI-93-31): (Tech. Rep. No. UMTRI-93-31). Ann Arbor, MI: University of Michigan Transportation Research Institute.

Green, P., Levison, W., Paelke, G., \& Serafin, C. (1995). Preliminary human factors guidelines for driver information systems (No. UMTRI Technical Report No. 93-21). Michigan: Ann Arbor: University of Michigan Transportation Research Institute.

Hart, S. G., \& Staveland, L. E. (1988). Development of NASA-TLX (Task Load Index): results of empirical and theoretical research. In N. Meshkati (Ed.), Human Mental Workload (pp. 139-183). Amsterdam: North-Holland.

Hirtle, S. C., \& Hudson, J. (1991). Acquisition of spatial knowledge for routes. Journal of environmental psychology, 11, 335-345.

Hirtle, S. C., \& Jonides, J. (1985). Evidence of hierarchies in cognitive maps. Memory \& Cognition, 13(3), 208-217.

Holding, C. S. (1992). Clusters and reference points in cognitive representations of the environment. Journal of Environmental Psychology, 12, 45-55.

Jackson, P. G. (1998). In search of better route guidance instructions. Ergonomics, 41(7), 1000-1013.

Jeffrey, D. J. (1981). Ways and means for improving driver route guidance (Laboratory report No. 1016): TRL.

Kaplan, S. (1976). Adaption, structure and knowledge. In G. T. Moore, Golledge, R.G. (Ed.), Environmental Knowing: theories, research and methods (pp. 32-45). Stroudsburg: Dowden, Hutchinson and Ross Inc.

King, G. F. (1986). Driver performance in highway navigation tasks. Transportation research record(1093), 1-11. 
Lee, J. D., Caven, B., Haake, S., \& Brown, T. L. (2001). Speech-Based Interaction with InVehicle Computers: The Effect of Speech-Based E-Mail on Drivers' Attention to the Roadway. Human Factors, 43(4), 631-640.

Lunenfield, H. (1989). Human factors considerations of motorist navigation and information systems. Paper presented at the Vehicle Navigation and Information Systems.

Lynch, K. (1960). The Image of the City. Cambridge, Mass: MIT Press.

May, A. J., Ross, T., \& Bayer, S. H. (2003). Drivers' Information Requirements when Navigating in an Urban Environment. Journal of Navigation, 56(1), 89-100.

Mollenhauer, M. A., Hulse, M. C., Dingus, T. A., Jahns, S. K., \& Carney, C. (1997). Design decision aids and human factors guidelines for ATIS displays. In Y. I. Noy (Ed.), Ergonomics and Safety of Intelligent Driver Interfaces (pp. 23-61). Mahwah, New Jersey: Lawrence Erlbaum Associates, Inc.

Nygren, T. E. (1991). Psychometric properties of subjective workload measurement techniques: Implications for their use in the assessment of perceived mental workload. Human Factors, 33, 17-31.

Passini, R. (1984). Spatial representations, a wayfinding perspective. Journal of environmental psychology, 4(153-164).

Philips, B. H. (1999, September 27-October 1, 1999). The Role of Landmark Information in Intelligent Navigation Displays. Paper presented at the Houston... We Have a Solution!, Proceedings of the Human Factors and Ergonomics Society 43rd Annual Meeting. HFES, Santa Monica.

Rowell, J. M. (2001). Applying map databases to advanced navigation and driver assistance systems. Journal of Navigation, 54(3), 355-363. 
Sadalla, E. K., Burroughs, W. J., \& Staplin, L. J. (1980). Reference points in spatial cognition. Journal of experimental psychology: human learning and memory, 6(5), 516-528.

Siegel, S., \& Castellan, N. J. J. (1988). Nonparametric Statistics for the Behavioural Sciences (2nd ed.). New York: McGraw Hill.

Streeter, L. A., Vitello, D. (1986). A profile of drivers' map-reading abilities. Human factors, 28(2), 223-239.

Tolman, E. C. (1948). Cognitive maps in rats and men. Psychological Review, 55, 189-208.

Tom, A., \& Denis, M. (2003). Referring to Landmark or Street Information in Route Directions: What Difference Does It Make? In S. Timpf (Ed.), COSIT 2003 Lecture Notes in Computer Science 2825 (pp. 362-374). Berlin: Springer-Verlag.

Trowbridge, C. C. (1913). On Fundamental Methods of Orientation and 'Imaginary Maps'. Science, 38(888-897).

Walker, J., Alicandri, E., Sedney, C., \& Roberts, K. (1991). In-vehicle navigation devices: effects on the safety of driver performance. Paper presented at the Vehicle Navigation and Information Systems, Dearborn, Michigan.

Ward, S. L., Newcombe, N., Overton, W.F. (1986). Turn left at the church or 3 miles north a study of direction giving and sex differences. Behaviour and environment, 18(2), 192-213.

Wierwille, W. W. (1993). Visual and manual demands of in-car controls and displays. In B. Peacock, Karwowski, W. (Ed.), Automotive Ergonomics (pp. 299-320). London: Taylor and Francis.

Wierwille, W. W., Antin, J. F., Dingus, T. A., \& Hulse, M. C. (1989). Visual attentional demand of an in-car navigation display system. In A. G. Gale (Ed.), Vision in vehicles II (pp. 307-316): London: Elsevier Science. 
Wochinger, K., \& Boehm-Davis, D. (1997). Navigational preference and driver acceptance of advanced traveler information systems. In I. Y. Noy (Ed.), Ergonomics and safety of intelligent driver interfaces (pp. 345-362). Mahwah, NJ: Lawrence Erlbaum Associates. 


\section{List of tables}

TABLE 1: Summary of manoeuvres and accompanying landmarks

\section{List of figures}

Figure 1. The visual information shown on approach to each manoeuvre. Each distance bar represents approx. 50m (system used yards); they empty from bottom upwards.

Figure 2. The effect of information category on (a) the mean number of glances made to the display, and (b) \% moving time spent glancing to the display during the approach to a manoeuvre (means: good landmarks: 5.9/10.5\%, poor landmarks: 5.1/9.3\%, distance information: 10.0/16.7\%). Error bars represent 95\% confidence interval of the mean in all cases.

Figure 3. The effect of information category on the mean driver confidence (1: 'low'; 2 : 'medium'; 3: 'high') at the Preview 1, Preview 2 and Final message points, and Postmanoeuvre.

Figure 4. The effect of information category on the severity of errors and total driving error score per participant group $(\mathrm{N}=16,16,16)$.

Figure 5. The effect of information category on the total of navigation errors made, per participant group 
TABLE 1: Summary of manoeuvres and accompanying landmarks

\begin{tabular}{|c|c|c|}
\hline Manoeuvre & Good landmark & Poor landmark \\
\hline $\begin{array}{l}\text { Right turn off a } \\
\text { dual carriageway }\end{array}$ & $\begin{array}{l}\text { Traffic lights at the } \\
\text { turn }\end{array}$ & $\begin{array}{l}\text { A distinctive sculpture } \\
\text { (height } 3 m \text { ) }\end{array}$ \\
\hline $\begin{array}{l}\text { Right turn off a } \\
\text { dual carriageway }\end{array}$ & Petrol station & $\begin{array}{l}\text { Public house, } \\
\text { terraced, set back } 4 \mathrm{~m} \\
\text { from the carriageway }\end{array}$ \\
\hline $\begin{array}{l}\text { Left turn off a } \\
\text { single carriageway }\end{array}$ & Pedestrian lights* & Bus stop \\
\hline $\begin{array}{l}\text { Left turn off a } \\
\text { single carriageway }\end{array}$ & $\begin{array}{l}\text { Public house, } \\
\text { distinctive, detached }\end{array}$ & Bus stop \\
\hline $\begin{array}{l}\text { Left turn off a } \\
\text { single carriageway }\end{array}$ & Pedestrian lights* & Post box \\
\hline $\begin{array}{l}\text { Right turn off a } \\
\text { single carriageway }\end{array}$ & Pedestrian lights* & $\begin{array}{l}\text { Bridge on the current } \\
\text { road (to travel over) }\end{array}$ \\
\hline $\begin{array}{l}\text { Right turn off a } \\
\text { single carriageway }\end{array}$ & Pedestrian lights* & Post box \\
\hline $\begin{array}{l}\text { Right turn off a } \\
\text { single carriageway }\end{array}$ & Pedestrian lights* & Telephone box \\
\hline
\end{tabular}

* Of similar appearance to traffic lights 


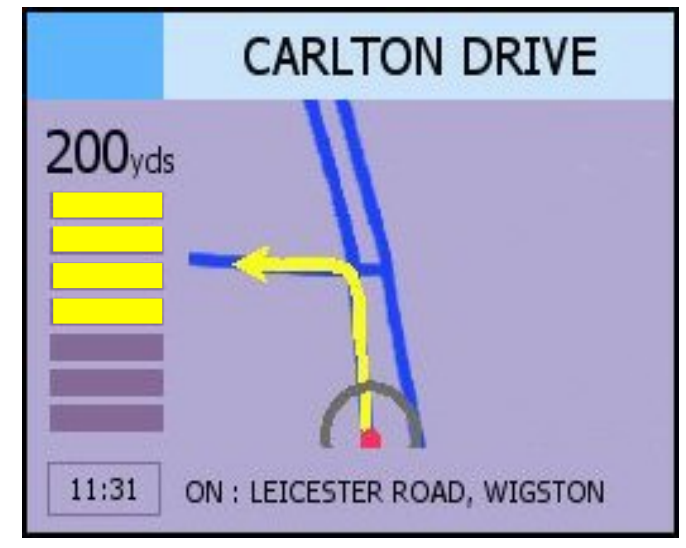

Figure 1. The visual information shown on approach to each manoeuvre. Each distance bar represents approx. 50m (system used yards); they empty from bottom upwards. 

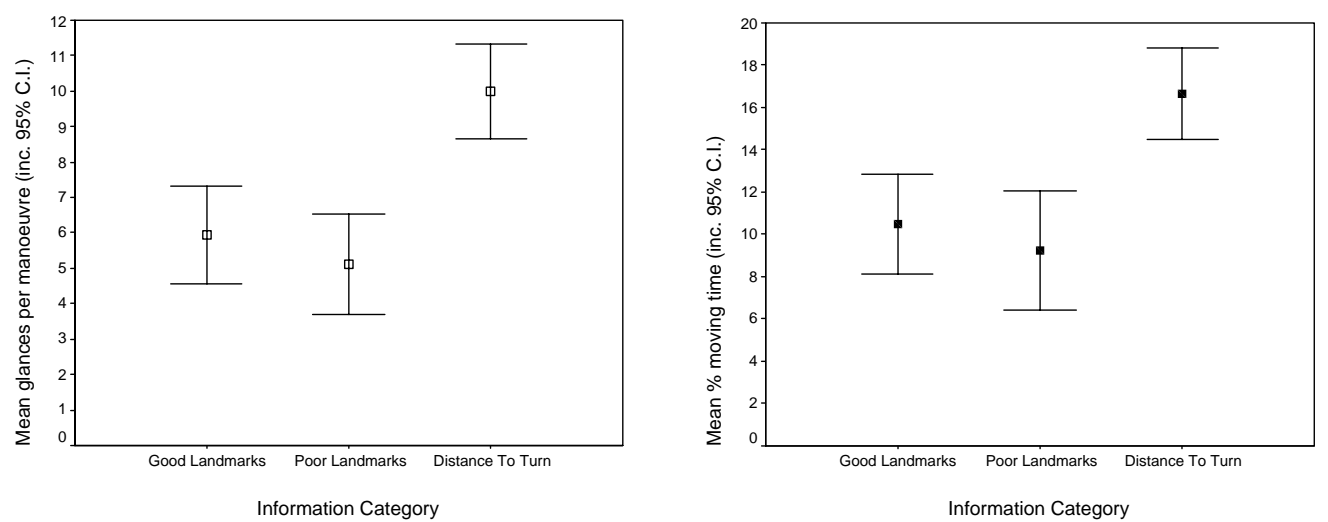

Figure 2. The effect of information category on (a) the mean number of glances made to the display, and (b) \% moving time spent glancing to the display during the approach to a manoeuvre (means: good landmarks: 5.9/10.5\%, poor landmarks: 5.1/9.3\%, distance information: 10.0/16.7\%). Error bars represent 95\% confidence interval of the mean in all cases. 


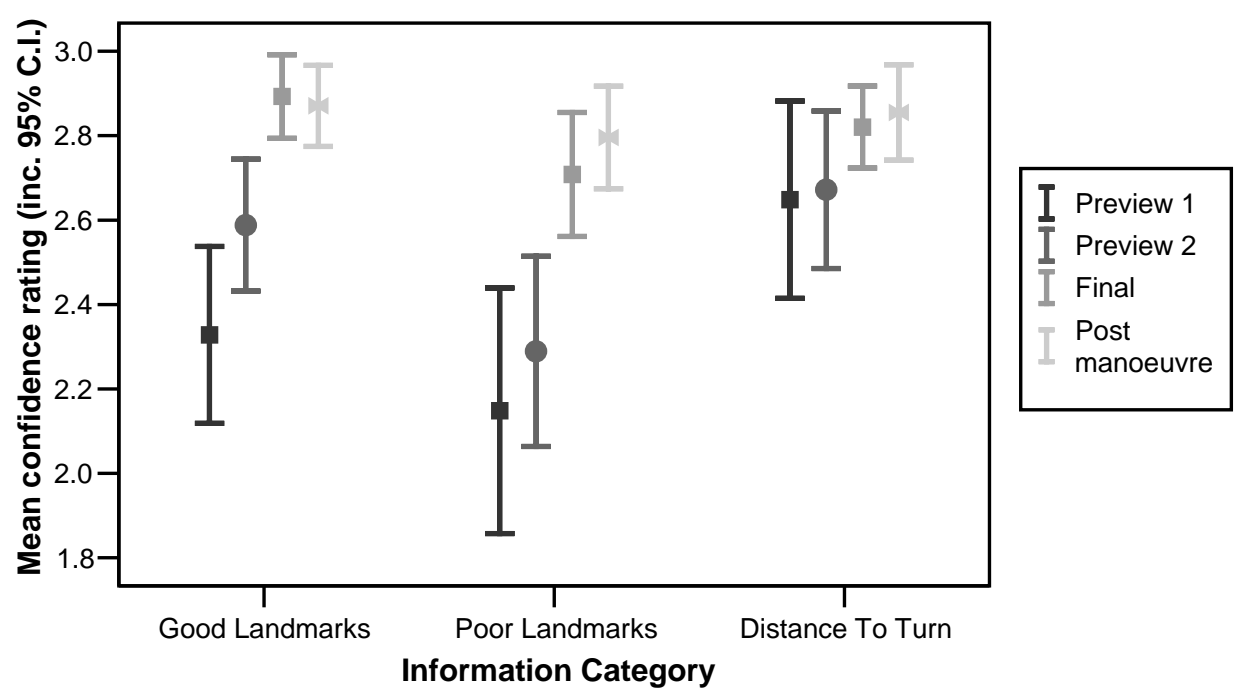

Figure 3. The effect of information category on the mean driver confidence (1: 'low'; 2 : 'medium'; 3: 'high') at the Preview 1, Preview 2 and Final message points, and Postmanoeuvre. Error bars represent $95 \%$ confidence interval of the mean in all cases. 


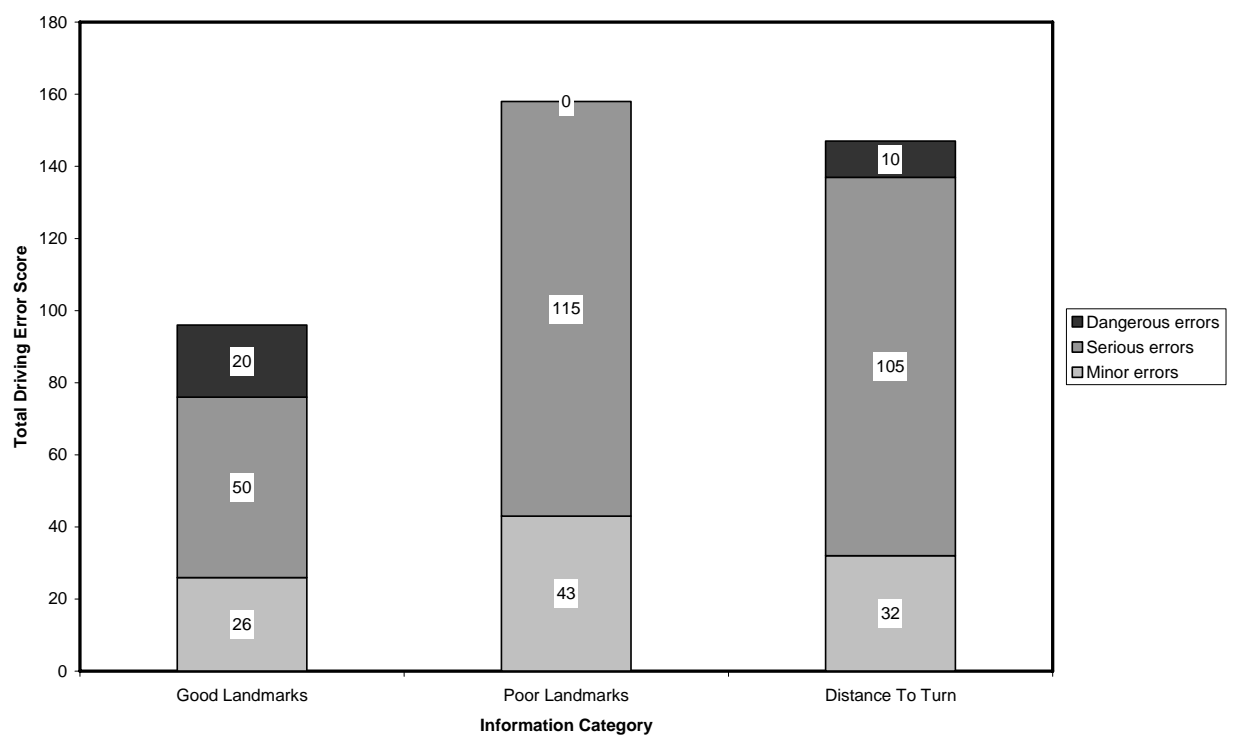

Figure 4. The effect of information category on the severity of errors and total driving error score per participant group $(\mathrm{N}=16,16,16)$. 


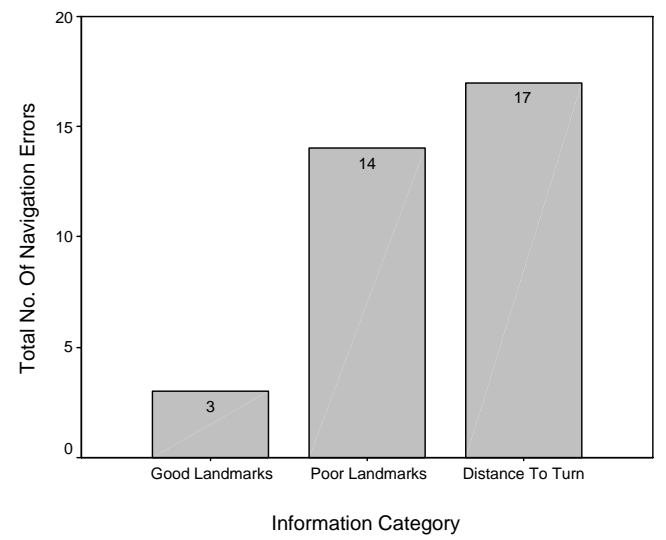

Figure 5. The effect of information category on the total of navigation errors made, per participant group $(\mathrm{N}=16,16,16)$. 


\section{Biographies:}

Andrew May and Tracy Ross are human factors research fellows within the Applied Ergonomics Centre at ESRI (Ergonomics \& Safety Research Institute) at Loughborough University. Andrew received his MSc in Ergonomics and Human Factors from University College London in 1993. Tracy received her BSc in Ergonomics from Loughborough University in 1987. 